Ivan Paunović ${ }^{\mathbf{1}, \mathbf{2}}$, Milan Jovanović ${ }^{1}$, Branislav Rovčanin ${ }^{1}$, Vladan Živaljević ${ }^{1,2}$, Katarina Taušanovici ${ }^{1,2}$, Aleksandar Diklić1, ${ }^{1,2}$

\title{
PRIKAZ SLUČAJA PRVE LAPAROSKOPSKE ADRENALEKTOMIJE KOD FEOHROMOCITOMA U KLINIČKOM CENTRU SRBIJE
}

\begin{abstract}
Apstrakt: Uvod Endoskopska hirurgija je značajno napredovala i razvila se u poslednje dve decenije, i sada se laparoskopska adrenalektomija smatra kao metod izbora za lečenje feohromocitoma. Međutim, ova procedura je i dalje povezana sa visokom incidencom javljanja intraoperativne hipertenzije. U ovom radu je prikazan prvi slučaj laparoskopske adrenalektomije kod feohromocitoma u Srbiji.

Prikaz bolesnika Žena stara 55 godina upućena je u Centar radi operacije feohromocitoma leve nadbubrežne žlezde. Pacijent je imao klasične kliničke manifestacije feohromocitoma (hipertenzija, palpitacije, tahikardija, bol ispod levog rebarnog luka). CT i MR pregledom je identifikovana nekrotično-cistična ovalna formacija leve nadbubrežne žlezde, promera 50x48x48mm. U okviru preoperativne pripreme primenjeni su fenoksibenzamin, ACE inhibitori i rehidratacija. Leva laparaskopska adrenalektomija je izvedena kroz 3 porta (dva od $10 \mathrm{~mm}$ i jedan od $5 \mathrm{~mm}$ ). Anestezija je trajala 155 minuta, a operacija 125 minuta. U toku operacije nije bilo značajnih varijacija u krvnom pritisku, niti hipertenzivnih kriza. Pacijent je trećeg postoperativnog dana premešten na odeljenje endokrinologije, $\mathrm{i}$ tokom boravka u bolnici pacijent je bio normotenzivan.
\end{abstract}

1 Centar za endokrinu hirurgiju, Klinički centar Srbije, Beograd, Srbija;

2 Univerzitet u Beogradu, Medicinski fakultet, Beograd, Srbija; 
Zaključak Laparoskopska adrenalektomija predstavlja siguran i efikasan hirurški pristup za operacije feohromocitoma.

Ključne reči: laparoskopska adrenalektomija; feohromocitom; nadbubrežna žlezda.

Summary: Introduction Endoscopic surgery progressed and developed significantly during the last two decades and laparoscopic adrenalectomy is now considered as the treatment of choice for pheochromocytoma. Still, this procedure can be associated with high incidence of intraoperative hypertension. We present a case of the first laparoscopic adrenalectomy for pheochromocytoma in Serbia.

Case Outline A 55-year-old female was admitted to Center for surgery for pheochromocytoma of the left adrenal gland. Clinically patient acquires classical manifestation of pheochromocytoma (hypertension, palpitations, tachycardia and pain below the left rib cage). CT and MR revealed necrotic-cystic oval formation of the left adrenal gland, $50 \times 48 \times 48 \mathrm{~mm}$ in diameter. The pre-operative preparation was with phenoxybenzamine, ACE inhibitors and rehydratation prior the surgery. Left laparoscopic adrenalectomy was performed with 3 ports (two $10-\mathrm{mm}$ and one $5-\mathrm{mm}$ ports). The anesthesia lasted 155 minutes and the operation 125 minutes. Regarding the blood pressure there were no hypertension crises during the surgery. The patient was discharged on the $3^{\text {rd }}$ postoperative day to our endocrinology department, and during stay in our institution the patient was normotensive.

Conclusion Laparoscopic adrenalectomy is the safe and effective surgical method for pheochromocytoma surgery.

Keywords: laparoscopic adrenalectomy; pheochromocytoma; adrenal gland.

\section{Uvod}


Feohromocitomi predstavljaju kateholamin sekretujuće tumore porekla hromafinih ćelija [1]. Klinički znaci i simptomi kod pacijenata sa feohromocitomom su predstavljeni na Tabeli 1 [2, 3].

Godišnja incidencija feohromocitoma se kreće 2-5 slučajeva na milion stanovnika [4]. Smatra se da su ovi tumori odgovorni za hipertenziju kod 0,1 do $0,6 \%$ pacijenata među opštom populacijom $[4,5]$.

Hirurgija predstavlja definitivni način lečenja kod pacijenata sa feohromocitomom, nakon preoperativne pripreme sa $\alpha$ i $\beta$ adrenergičkim blokatorima. Pojačana sekrecija kateholamina, koja se javlja prilikom manipulacije tumorom i bolnih senzacija tokom operacije, predstavlja izazov kako za hirurga tako i za anesteziologa [6].

U današnje vreme laparoskopska adrenalektomija predstavlja operaciju izbora za pacijente sa feohromocitomom, bez obzira ne veličinu tumora [7]. Edukovani hirurški tim (hirurg i anesteziolog) smanjuju rizik nekontrolisane intraoperativne hipertenzije.

Prvu laparoskopsku adrenalektomiju kod feohromocitoma uradio je Mišel Ganje (Michael Gagner) 1992. godine [8].

U ovom radu predstavljamo prvi slučaj elektivne laparoskopske operacije kod pacijenta sa klinički manifestnim feohromocitomom u Kliničkom centru Srbije.

\section{Prikaz slučaja}

Pacijentkinja starosti 55 godina (visina $168 \mathrm{~cm}$, težina $65 \mathrm{~kg}$, BMI 23,01) primljena je u Centar za endokrinu hirurgiju Kliničkog centra Srbije zbog planirane laparoskopske adrenalektomije feohromocitoma sa leve strane.

Pored hipertenzije, pacijentkinja je navodila i podatak o gastroezofagealnom refluksu. Pacijentkinja je bila pušač, do 20 cigareta dnevno, negirala je alergije, prethodne operacije i konzumiranje alkohola i narkotika. Pre započinjanja terapije fenoksibenzaminom bila je prisutna hipertenzija (maksimalno do 180/100 $\mathrm{mmHg}$ ), sa povremenim palpitacijama, tahikardijom i bolom ispod levog rebarnog luka.

Noradrenalin je bio povišen, $2728 \mathrm{mmol} / 24 \mathrm{~h}$ (referentne vrednosti do 570 mmol/24h). Ostali parametri funkcije nadbubrega i štitaste žlezde su bile u granicama normale (Tabela 2). Ultrazvuk abdomena je pokazao tumorsku formaciju u predelu leve nadbubrežne žlezde; nakon toga, kompjuterizovanom tomografijom abdomena nađena je cistično nekrotična hipodenzna ovalna promena 
leve nadbubrežne žlezde promera 50x48x48 mm (Slika 1). Nalaz magnetne rezonance je pokazao jasno ograničenu kružnu formaciju promera $55 \times 45 \mathrm{~mm}$, homogeno hiperintenzivna na T2 sekvence, sa tečno-nekrotičnom komponentom u centralnom delu u nadbubrežnoj žlezdi. Preoperativna evaluacija je uključivala i ehokardiografski pregled (normalna struktura srca, ejekciona frakcija $72 \%$, bez ispada u kinetici i sa minimalnom aortnom regurgitacijom).

Preoperativna medikamentozna priprema se sastojala od $\alpha$-receptorskog blokatora - fenoksibenzamina, 4 nedelje pre operacije, u dozi od $10 \mathrm{mg}$ jednom dnevno, a nakon prve nedelje $10 \mathrm{mg}$, dva puta dnevno. Dodatno, uključen je i felodipin, 2,5 mg, jednom dnevno, 3 nedelje pre operacije. Kada je postignuta adekvatna kontrola krvnog pritiska, a rutinske biohemijske analize krvi i urina su bile $\mathrm{u}$ referentnim vrednostima, planirana je operacija.

Pola sata pre operacije pacijent je premidiciran sa $4 \mathrm{mg}$ midazolama i $0,5 \mathrm{mg}$ atropina. Anestezija je postignuta sa $5 \mathrm{mg}$ midazolama, $150 \mathrm{mg}$ propofola i 100 mcg fentanila. Mišićna relaksacija je postignuta korišćenjem $50 \mathrm{mg}$ rokuronijum-bromida. U cilju postizanja adekvatne dubine anestezije korišćen je sevofluran, u mešavini sa kiseonikom. Vitalni parametri su kontinuirano praćeni: saturacija kiseonika, kapnografija, invazivni krvni pritisak, srčani ritam, EKG i centralni venski pritisak.

Pacijent je postavljen u desni lateralni dekubitalni položaj (LTA - lateral transabdominal approach).

Pneumoperitoneum je kreiran Hasonovom tehnikom, uz postavljanje dva 10-mm i jednim 5-mm porta (Slika 2). Intraabdominalni pritisak $\mathrm{CO}_{2}$ je održavan između 12 i $14 \mathrm{mmHg}$. Korišćenjem harmonijskog skalpela slezina je mobilisana medijalno, presecanjem splenofreničnog ligamenta (Slika 3). Donja frenična vena i leva gastrična kurvatira su vizualizovane sa gornje strane. Korišćenjem hirurškog prostora između repa pankreasa i Gerotove fascije pristupljeno je gornjem polu nadbubrežne žlezde. Donje i srednje adrenalne arteriole su disekovane pre identifikacije leve adrenalne vene, na koju su postavljeni titanijumski klipsevi, a nakon toga je presečena (Slika 4). Nakon toga, feohromocitom je ekscidiran sa okolnim masnim tkivom. Postavljena je drenaža bez negativnog pritiska u adrenalnu ložu kroz donji port. Anestezija je trajala 155 minuta, a operacija 125 minuta. Tokom operacije krvni pritisak i srčani ritam su kontrolisani vazodilatorom (glicerilnitrat) i betablokatorom (metoprolol). Pacijent je bio stabilan tokom cele operacije - prosečan broj otkucaja srca je bio $72 / \mathrm{min}$, a prosečni sistolni arterijski 
pritisak je bio $122 \mathrm{mmHg}$ (Grafikon 1). Na kraju operacije primenjena je reverzija neuromuskularne blokade, a pacijent je ekstubiran i premešten na odeljenje poluintenzivne nege.

Tokom prvog postoperativnog dana kontrola bola je postignuta primenom tramadola (100 mg, na 8 sati), dok je drugog postoperativnog dana primenjen ketorolak (30 mg, na 6 sati). U postoperativnoj terapiji korišćeni su i antibiotici, antiemetici, niskomolekularni heparin i inhibitori protonske pumpe. Dren je uklonjen drugog postoperativnog dana, jer je količina dreniranog sadržaja bila ispod $100 \mathrm{~mL}$. Pacijent je premešten na odeljenje endokrinologije trećeg postoperativnog dana u dobrom opštem stanju.

Histopatološkom analizom preparata postavljena je dijagnoza benignog feohromocitoma. Na prvoj postoperativnoj kontroli mesec dana nakon operacije pacijent je bio normotenzivan, a vrednosti kateholamina su bile u granicama normale.

\section{Diskusija}

U današnje vreme, laproskopska adrenalektomija (LA) predstavlja operaciju izbora kod feohromocitoma. Pre 1992. godine otvoreni pristup je bio operacija izbora kod ovih pacijenata. Prve uspešne operacije kod pacijenata sa feohromocitomom izveli Ru (Cesar Roux, 1857-1934), u Švajcarskoj, i Čarls Mejo (Charles Horace Mayo, 1865-1939) u SAD 1926. godine. (9)

Mišel Ganje (Michael Gagner) je 1992. godine objavio rad u kome je prikazao prve tri uspešne laparoskopske adrenalektomije. Korišćena je tehnika laparoskopskog lateralnog transperitonealnog pristupa (LTA - lateral transperitoneal approach) [8].

Laparoskopska adrenalektomija može se izvesti kroz transperitonealni i retroperitonealni pristup. Postoje dve opcije za transperitonealni pristup, lateralni i prednji [7]. U Centru za endokrinu hirurgiju Kliničkog centra Srbije koristimo LTA kao rutinsku proceduru od 2012. godine. Laparoskopska adrenalektomija predstavlja zlatni standard za male i funkcionalne i afunkcionalne tumore, za koje su na osnovu preoperativnog ispitivanja isključena maligna alteracija sa visokom sigurnošću [4, 7]. Međutim, kao i sve druge operativne tehnike, i LTA ima neka ograničenja. Relativna kontraindikacija za ovu tehniku je povišeni kardiopulmonalni rizik i perzistentna koagulopatija, dok su apsolutne 
kontraindikacije tumor veći od $15 \mathrm{~cm}$, prisutna lokalna invazija, suspektni adrenokortikalni karcinom i metastatski feohromocitom [10-12].

Mnoge studije su poredile hemodinamsku stabilnost tokom laparoskopske i otvorene hirurgije za feohromocitom. Rezultati ukazuju da ne postoje značajne razlike u incidenci i stepenu hemodinamske nestabilnosti, dužine operacije i gubitka krvi za ova dva pristupa [12-17]. Kim i saradnici [18] su čak pokazali da je procenat pacijenata sa intraoperativnom hipertenzivnom krizom manji kod LTA u odnosu na otvoreni pristup $(0,6 \pm 0,5 \%$ tokom LTA i $1,67 \pm 1,1 \%$ tokom otvorenog pristupa, $\mathrm{p}=0,0146)$. Ova studija je takođe pokazala da postoperativno započinjanje oralnog unosa je brže kod pacijenata koji su operisani laparoskopski $(1,1 \pm 0,3$ dana) $\mathrm{u}$ odnosu na otvoren pristup $(2,6 \pm 1,3$ dana, $\mathrm{p}=0,0037)$. Takođe, postoji statistički značajna razlika u dužini postoperativnog boravka (LTA 5,6 \pm 2 dana, u odnosu na otvoreni pristup 12,4 $\pm 3,5$ dana, $\mathrm{p}=0,0001)$. Takođe, manja je upotreba analgetika nakon laparoskopske u odnosu na otvorenu operaciju. Slične rezultate su našle i ostale studije koje su se bavile upoređivanjem laparoskopske i otvorene hirurgije. Pacijent koga smo prezentovali nije imao intraoperativnu hipertenzivnu krizu, peroralni unos hrane $i$ tečnosti je započet drugog postoperativnog dana, kontrola bola je postignuta minimalnom dozom analgetika i pacijent je otpušten trećeg postoperativnog dana.

Sa druge strane, ne postoje razlike između feohromocitoma i drugih adrenalnih tumora koji su operisani laparoskopskim pristupom, kada se posmatraju gubitak krvi, procenat konverzije u otvoreni pristup, postoperativni boravak, postoperativni nivo hemoglobina, potreba za transfuzijom krvi, javljanje perioperativnih komplikacija, veličine tumora i ASA status [19, 21, 22].

Glavni tehnički problem prilikom operacije feohromocitoma, bez obzira na hirurški pristup (otvoreni ili laparoskopski), je identifikacija srednje adrenalne vene. Kod otvorenog pristupa presecanje vene je u većini slučajeva moguće nakon intraoperativne mobilizacije tumora, što je povezano sa hipertenzivnom krizom [20]. To predstavlja razlog zašto su Fernandez-Kruz i saradnici [23] pre 20 godina demonstrirali da laparoskopski pristup feohromocitomu smanjuje intraoperativno oslobađanje kateholamina $\mathrm{u}$ manjoj meri u odnosu na otvoreni pristup, što posledično smanjuje rizik za hipertenzivnu krizu, zato što se tokom operacije minimalno manipuliše tumorom. Ove nalaze su potvrdile i druge studije [13, 24]. Iako laparoskopski pristup poboljšava vizualizaciju adrenalne vene, iz našeg iskustva ponekad je to veoma otežano zbog okolnog masnog tkiva. 
Laparoskopsku adrenalektomiju zbog feohromocitoma treba da izvodi iskusan endokrini hirurg. Ovo je veoma bitno jer, prema podacima iz literature, konverzija u otvorenu hirurgiju iznosi oko $2 \%$, a konverziju može uraditi samo hirurg koji je iskusan u otvorenoj adrenalektomiji [10]. Glavni razlog za konverziju predstavlja nekontrolisano krvarenje, adhezije, gojaznost, povreda okolnih organa, hernije, uvećana jetra ili nedostatak iskustva hirurga $[10-12,25,26]$. Šen i saradnici su pokazali da gojaznost (BMI preko $\left.24 \mathrm{~kg} / \mathrm{m}^{2}\right)$ i veličina tumora $(\geq 5 \mathrm{~cm}) \mathrm{kod}$ feohromocitoma predstavljaju prediktivni faktor za konverziju [25].

Slučaj koji prezentujemo prema nalazima ove studije bio je u visokom riziku za konverziju, a razlog zašto se nije dogodila je u tome što smo pre ovog slučaja izveli preko 100 LTA za druge funkcionalne i afunkcionalne tumore nadbubrega.

Iz našeg iskustva, kao i iz podataka iz literature, LTA je povezana sa ređim komplikacijama $\mathrm{u}$ odnosu na otvoreni pristup (npr. respiratorne i infekcije rane, manja incidencija povrede organa) [25-27].

$\mathrm{Na}$ osnovu našeg iskustva, laparoskopska adrenalektomija za feohromocitom je sigurna i efikasna hirurška procedura. Osnove za dobar ishod su precizna vizualizaciona dijagnostika, kao i preoperativno i intraoperativno postupanje. Neophodno je da se ova vrsta operacije izvodi od strane iskusnog i dobro koordinisanog hirurškog i anesteziološkog tima.

Tabela 1. Klinički simptomi i znaci karakteristični kod pacijenata sa feohromocitomom

\begin{tabular}{ll}
\hline Simptomi & $\%$ \\
\hline Glavobolja & $70-90$ \\
Palpitacije \pm tahikardija & $50-70$ \\
Diaforeza & $60-70$ \\
Anksioznost & 20 \\
Nervoza & $35-40$ \\
Abdominalni bol & $20-50$ \\
Mučnina & $26-43$ \\
Povraćanje & $15-40$ \\
Dispneja & $11-19$ \\
Vrtoglavica & $3-11$ \\
Netolerancija toplote & $13-15$
\end{tabular}




\begin{tabular}{ll} 
Parestezije & do 11 \\
Vizualni simptomi & $3-21$ \\
Konstipacija & 10 \\
Dijareja & 6 \\
\hline Znaci & \\
\hline Hipertenzija & $90-10$ \\
Paroksizmi & 50 \\
Ortostatska hipotenzija & 12 \\
Bledilo & $30-60$ \\
Crvenilo & 18 \\
Febrilnost & do 66 \\
Hiperglikemija & 42 \\
Povraćanje & $26-43$ \\
Konvulzije & $3-5$
\end{tabular}

Tabela 2. Vrednosti adrenalnih i tiroidnih hormona

Table 2. Adrenal and thyroid gland hormone values

\begin{tabular}{lll}
\hline Test & Vrednost & Referentne vrednosti \\
\hline kortizol & $306 \mathrm{nmol} / \mathrm{L}$ & $131-642$ \\
ACTH & $15 \mathrm{ng} / \mathrm{L}$ & $10-90$ \\
adrenalin & $15,2 \mathrm{ng} / \mathrm{L}$ & $<150$ \\
noradrenalin & $\underline{\mathbf{2 7 2 8}} \mathrm{ng} / \mathrm{L}$ & $<570$ \\
dopamin & $1378.7 \mathrm{ng} / \mathrm{L}$ & $<3240$ \\
FSH & $37.4 \mathrm{IU} / \mathrm{L}$ & $40-200$ \\
LH & $22.7 \mathrm{IU} / \mathrm{L}$ & $40-200$ \\
PTH & $76 \mathrm{ng} / \mathrm{L}$ & $0-80$ \\
Serumski kalcijum & $2,47 \mathrm{mmol} / \mathrm{L}$ & $2,15-2,65$ \\
TSH & $2,7 \mathrm{mIU} / \mathrm{L}$ & $0,3-5,5$ \\
FT4 & $12,5 \mathrm{ng} / \mathrm{L}$ & $7-18$
\end{tabular}




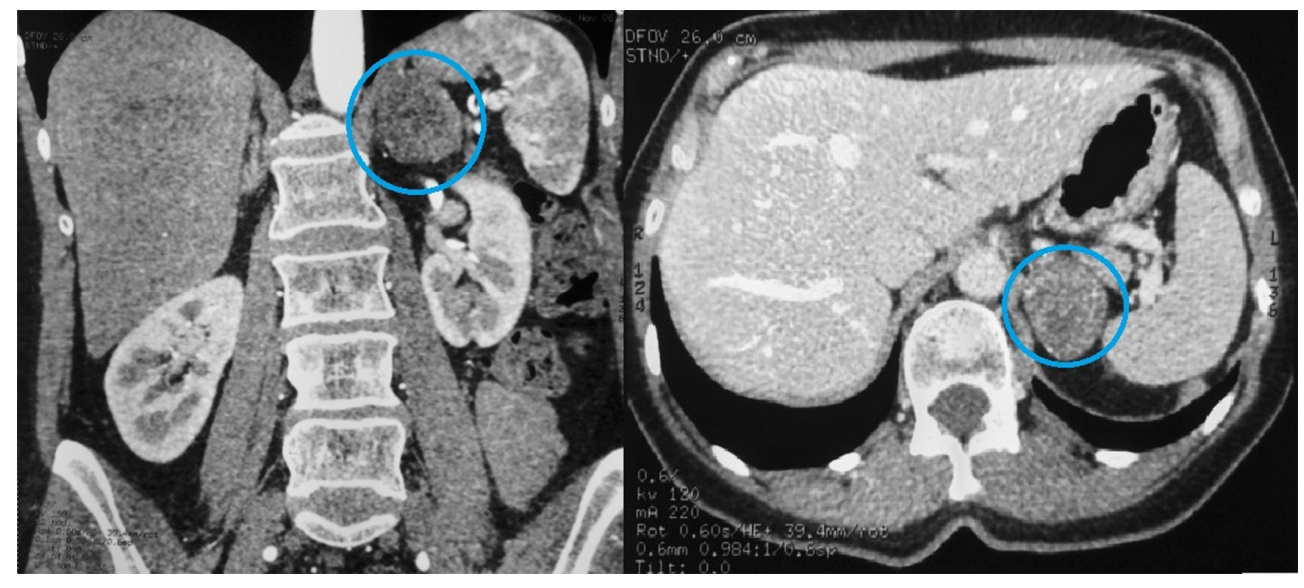

Slika 1. Tumor leve nadbubrežne žlezde na CT pregledu abdomena (frontalni i horizontalni presek) - zaokruženo 


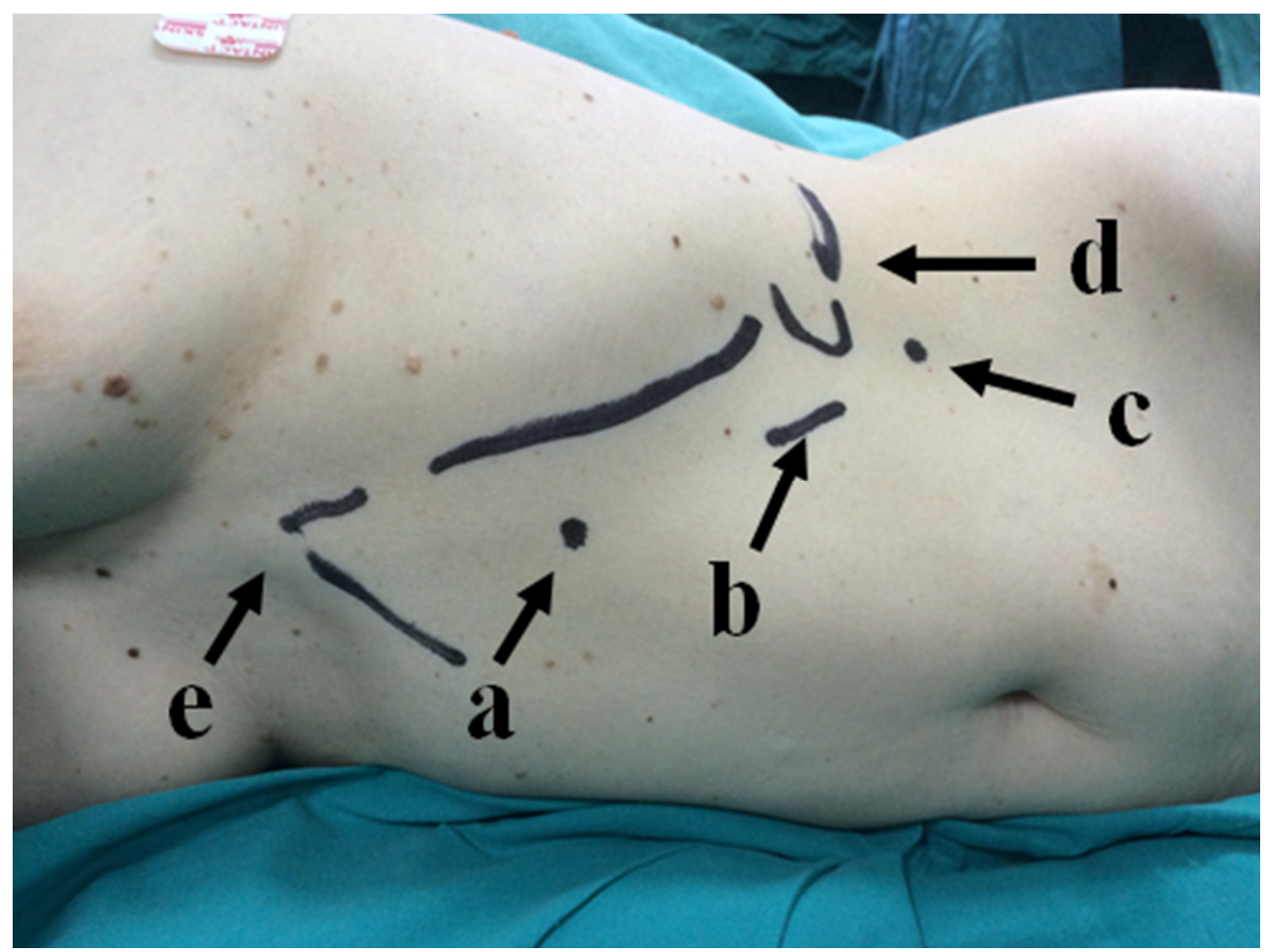

Slika 2. Elementi orijentacije za plasiranje troakara za levu laparoskopsku adrenalektomiju: $a-10 \mathrm{~mm}$ troakar; $b-10 \mathrm{~mm}$ troakar, port za kameru; $c-10 \mathrm{~mm}$ troakar; $d$-vrh 12. rebra; $e$-ksifoid. 


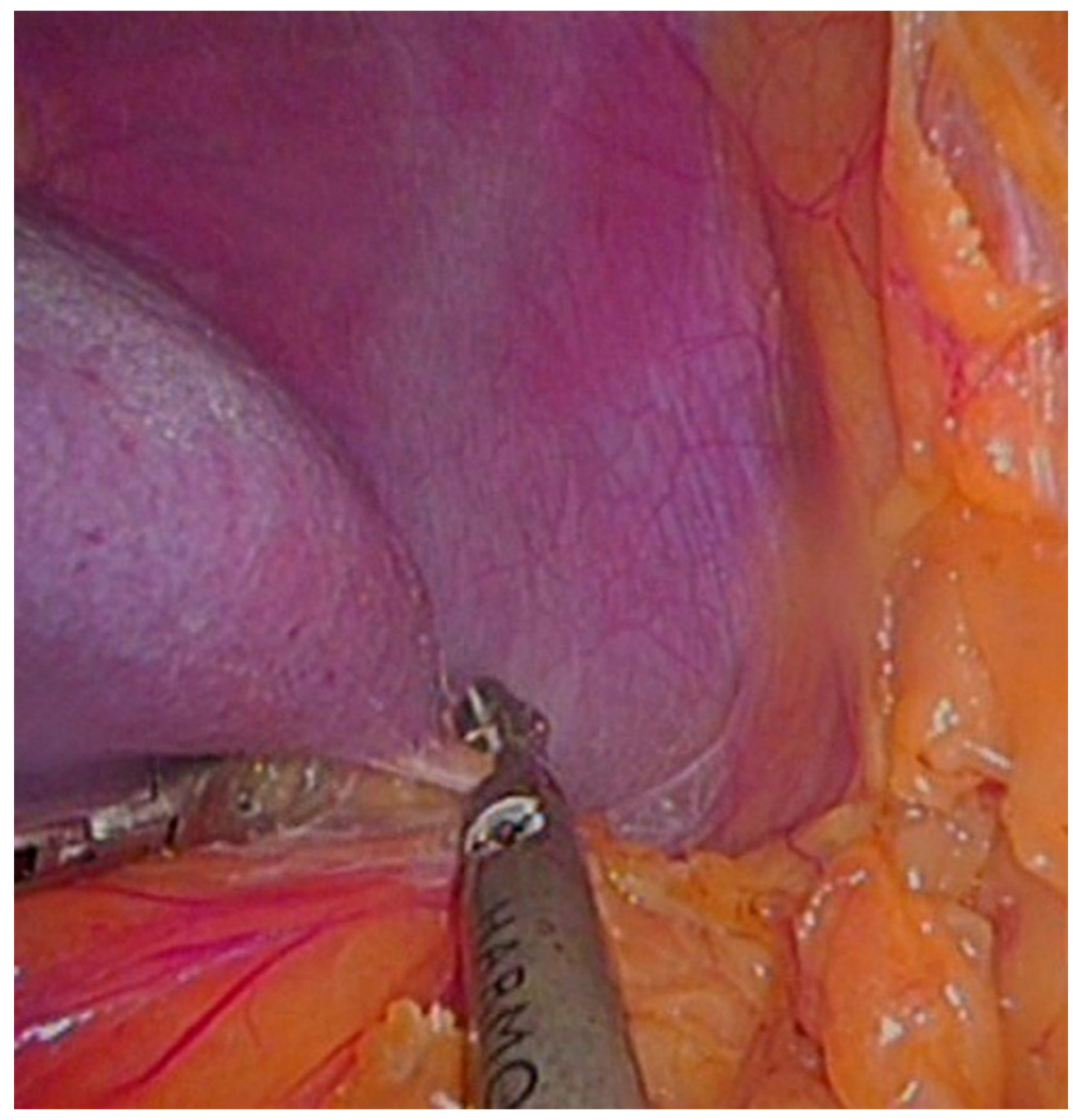

Slika 3. Presecanje splenofreničnog ligamenta 


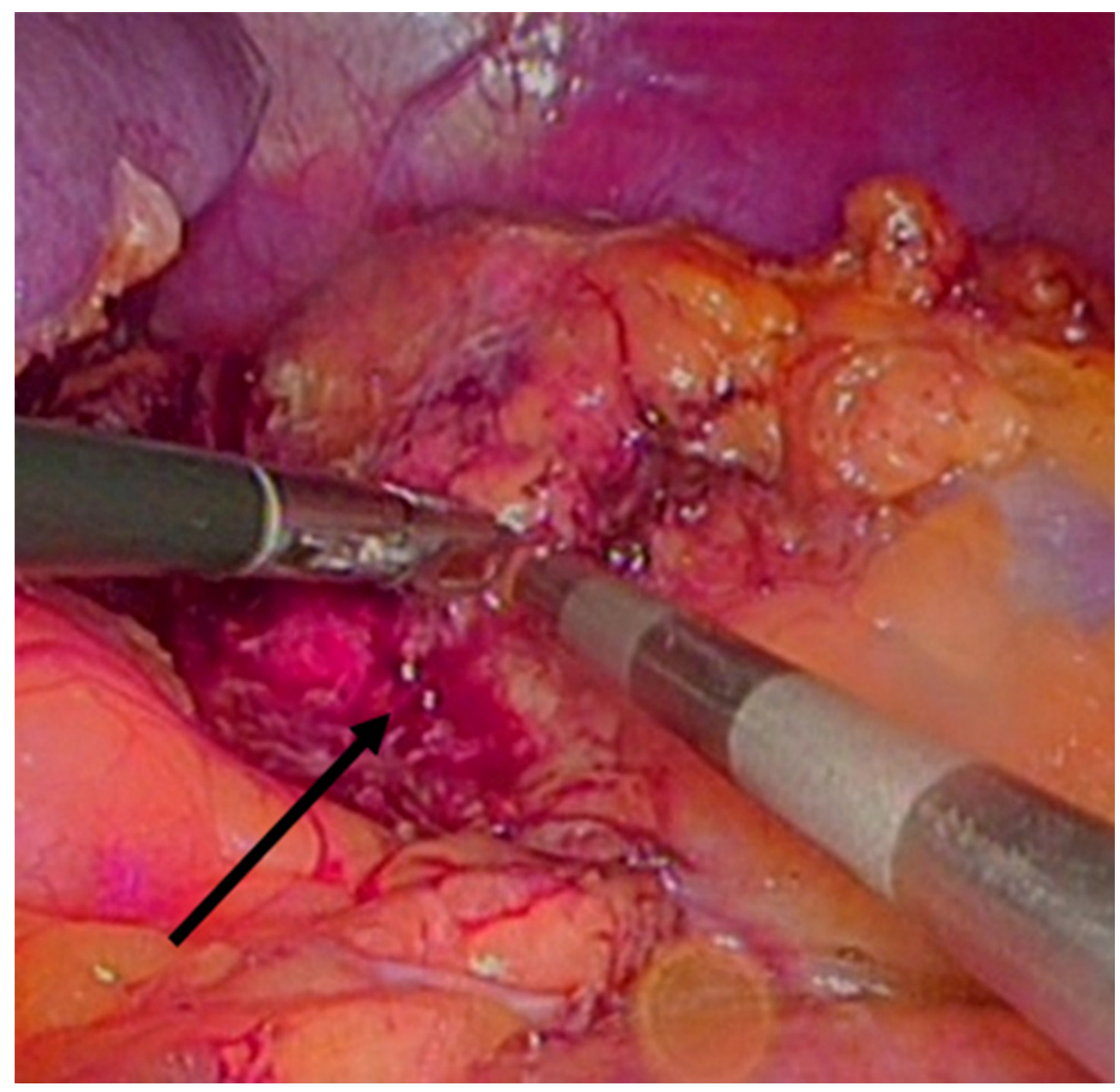

Slika 4. Postavljanje klipsa na adrenalnu venu - strelica 


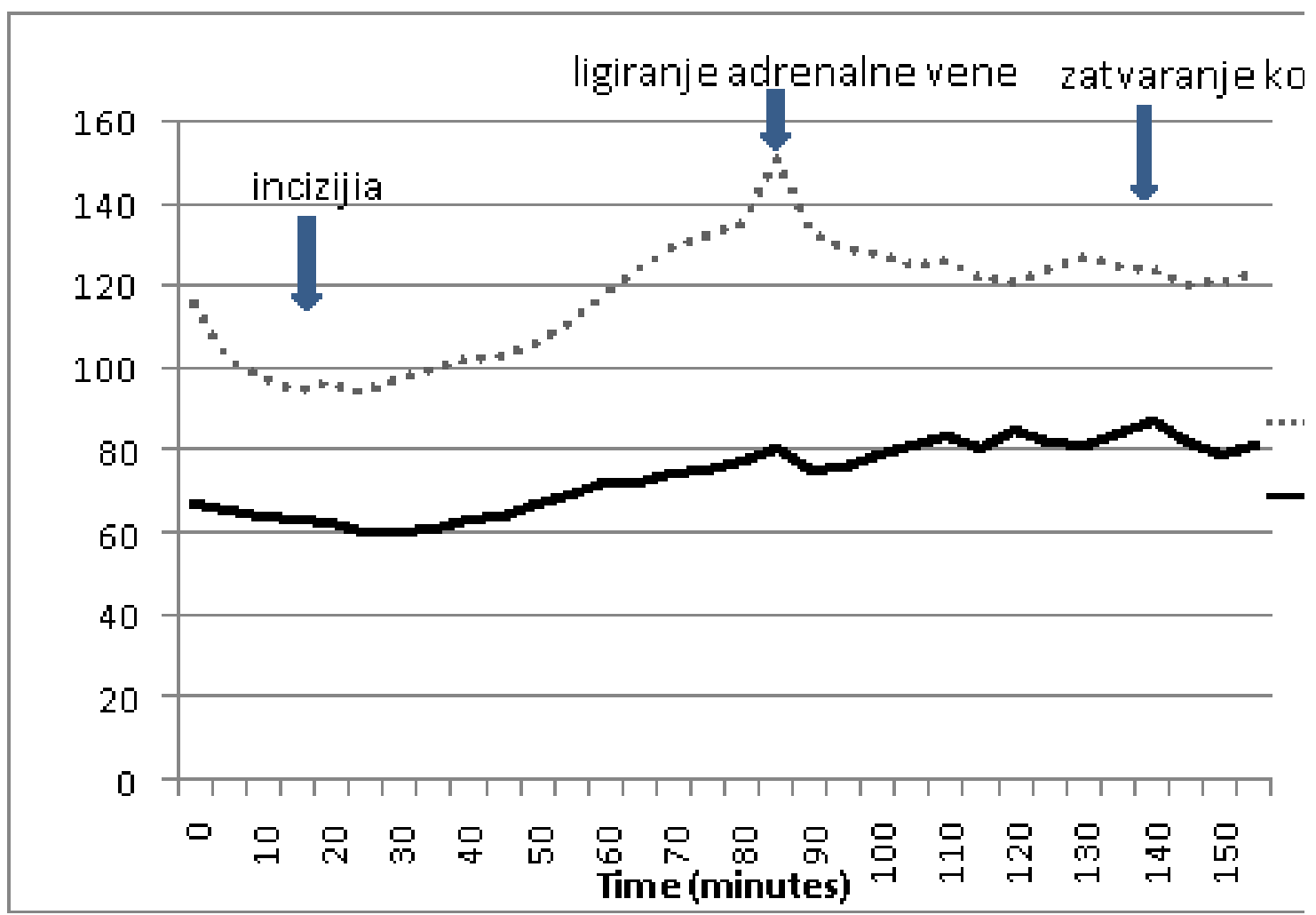

Grafikon 1. Promene sistolnog krvnog pritiska (SBP) i srčane frekvence (HR) tokom vremena u toku laparoskopske adrenalektomije

\section{Literatura}

Nakao K, Itoh H, Takaya K. Current topics in pheochromocytoma. Biomed Pharmacother. 2000, 54: 124-128.

Hull C. Pheochromocytoma: diagnosis, preoperative preparation and anaesthetic management. Br J Anaesth. 1986; 58:1453-68.

Ram CV, Fierro-Carrion GA. Pheochromocytoma. Semin Nephro. 1995; 1 15:126-37.

Eisenhofer G, Pacak K, Maher ER, Young WF, de Krijger RR. Pheochromocytoma. Clin Chem. 2013; 59: 466-472. 
Mazzaglia PJ. Hereditary pheochromocytoma and paraganglioma. J Surg Oncol. 2012; 106: 580-585.

Kinney M, Warner M, vanHeerden J, Horlocker T, Young W, Schroeder D et al. Perianesthetic risks and outcomes of pheochromocytoma and paraganglioma resection. Anesth Analg. 2000; 91: 1118-23.

Al-Zahrani HM. Laparoscopic adrenalectomy: An update. Arab J Urol, 2012; 10 (1): 56-65.

Gagner M, Lacroix A, Bolte E. Laparoscopic adrenalectomy in Cushing's syndrome and pheochromocytoma. N Engl j Med, 1992; 327(14), 1033.

Mayo CH. Paroxysmal hypertension with tumor of the retroperitoneal nerve. JAMA. 1927; 89:1047.

Rodríguez-Hermosa JI, Roig-García J, Font-Pascual JA, Sala MR, Muro PO, Badla BP et al. Evolution of laparoscopic adrenal surgery in a general surgery department. Cir Esp. 2008; 83: 205-10.

Assalia A, Gagner M. Laparoscopic adrenalectomy. Br J Surg. 2004; 91:1259-74.

Gumbs AA, Gagner M. Laparoscopic adrenalectomy. Best Pract Res Clin Endocrinol Metab. 2006; 20: 483-99.

Inabnet, William B, Bernard D, Chapuis Y. Comparison of the hemodynamic parameters of open and laparoscopic adrenalectomy for pheochromocytoma. World J Surg. 2000; 24(5): 574-8.

Sprung J, O'Hara JF, Gill IS, Abdelmalak B, Sarnaik A, Bravo EL. Anesthetic aspects of laparoscopic and open adrenalectomy for pheochromocytoma. Urology. 2000; 55 (3): 339-43.

Mobius E, Nies C, Ruthmund M. Surgical treatment of pheochromocytomas: laparoscopic or conventional? Surg Endosc. 1999; 13: 35-9.

Tiberio GA, Baiocchi GL, Arru L, Rosei CA, De Ponti S, Matheis A, et al. Prospective randomized comparison of laparoscopic versus open adrenalectomy for sporadic pheochromocytoma. Surg Endosc. 2008; 22(6): 1435-9.

Agarwal G, Sadacharan D, Aggarwal V, Chand G, Mishra A, Agarwal A. Surgical management of organ-contained unilateral pheochromocytoma: comparative outcomes of laparoscopic and conventional open surgical procedures in a large single-institution series. Langenbecks Arch Surg. 2012; 397(7): 1109-16.

Kim HH, Gee HK, GyungTS. Laparoscopic adrenalectomy for pheochromocytoma: comparison with conventional open adrenalectomy. J Endourol. 2004; 18(3): 251-5.

Tanaka M, Tokuda N, Koga H, Kimoto Y, Naito S. Laparoscopic adrenalectomy for pheochromocytoma: comparison with open adrenalectomy and comparison of laparoscopic surgery for pheochromocytoma versus other adrenal tumors. J Endourol. 2000; 14 (5), 427-31. 
Edwin B, Kazaryan AM, Mala T, Pfeffer PF, Tønnessen TI, Fosse E. Laparoscopic and open surgery for pheochromocytoma. BMC Surg. 2001; 1 (1): 2.

Mellon MJ, Sundaram CP. Laparoscopic adrenalectomy for pheochromocytoma versus other surgical indications. JSLS. 2008; 12 (4): 380-4.

Nguyen PH, Keller JE, Novitsky YW, Heniford BT, Kercher KW. Laparoscopic approach to adrenalectomy: review of perioperative outcomes in a single center. Am Surg. 2011; 77 (5): 592-6.

Fernández-Cruz L, Taurá P, Sáenz A, Benarroch G, Sabater L. Laparoscopic approach to pheochromocytoma: hemodynamic changes and catecholamine secretion. World J Surg. 1996; 20 (7): 762-8.

Giovanni R, Mercantini P, Amodio P, Buniva P, D'Angelo F, Petrocca S et al. Ten years of laparoscopic adrenalectomy: lesson learned from 104 procedures. Am Surg, 2005; 71 (4): 321-5.

Shen ZJ, Chen SW, Wang S, Jin XD, Chen J, Zhu Y et al. Predictive factors for open conversion of laparoscopic adrenalectomy: a 13-year review of 456 cases. J Endourol. 2007; 21: 1333-8.

Gaujoux S, Bonnet S, Leconte M, Zohar S, Bertherat J, Bertagna X et al. Risk factors for conversion and complications after unilateral laparoscopic adrenalectomy. Br J Surg. 2011; 98 (10): 1392-9.

Brunt LM. The positive impact of laparoscopic adrenalectomy on complications of adrenal surgery. Surg Endosc. 2002; 16 (2): 252-7. 